\title{
O ESTADO CAPITALISTA COMO FORMA SOCIAL
}

\section{RESUMO}

\author{
Pedro Rozales Rodero Dominczak \\ Amanda Aparecida Marcatti
}

O objetivo deste trabalho é apresentar uma leitura crítica do Estado capitalista, como forma social. Marx descreve e desenvolve no livro I d' 0 Capital, o capital em geral, que existe nos inúmeros capitais particulares que concorrem entre si na lógica de acumulação capitalista, porém difere deles, pois constitui natureza comum às múltiplas formas de capital. Portanto, pretendemos partir do mesmo nível de abstração onde se encontra o capital em geral para compreender o Estado capitalista, não só como uma instituição político-jurídica, mas como uma forma social, intrínseca a reprodução capitalista. Esta diferenciação entre o capital em geral e os capitais particulares nada mais é que uma diferença do nível de abstração sob o qual se observa o movimento de uma mesma categoria. Assim, o que se propõe neste trabalho é que, da mesma forma que o capital deve ser analisado sob um duplo aspecto, o da aparência e o da essência, também o Estado capitalista deve ganhar o mesmo tratamento.

Palavras-Chave: Estado capitalista; forma social; regime político.

\section{EL ESTADO CAPITALISTA COMO FORMA SOCIAL}

\section{RESUMEN}

El objetivo de este artículo es presentar una lectura crítica del estado capitalista como forma social. Marx describe y desarrolla en el libro I d 'Capital, el capital en general, que existe en las innumerables capitales particulares que compiten entre sí en la lógica de la acumulación capitalista, pero difiere de ellas en que es una naturaleza común a múltiples formas de capital. Por lo tanto, tenemos la intención de comenzar desde el mismo nivel de abstracción donde el capital en general es entender al estado capitalista, no solo como una institución político-legal, sino como una forma social, intrínseca a la reproducción capitalista. Esta diferenciación entre capital en general y capital privado no es más que una diferencia en el nivel de abstracción bajo el cual se observa el movimiento de la misma categoría. Por lo tanto, lo que se propone en este documento es que, así como el capital debe analizarse bajo un doble aspecto, el de la apariencia y la esencia, también el estado capitalista debe obtener el mismo tratamiento. 
Palabras clave: Estado capitalista; forma social régimen político.

\title{
THE CAPITALIST STATE AS AN SOCIAL FORM
}

\begin{abstract}
The aim of this paper is to present a critical reading of the capitalist state as a social form. Marx describes and develops in the book I d 'Capital, the capital in general, which exists in the innumerable particular capitals that compete against each other in the logic of capitalist accumulation, but differs from them in that it is a nature common to multiple forms of capital. Therefore, we intend to start from the same level of abstraction where capital in general is to understand the capitalist state, not only as a political-legal institution, but as a social form, intrinsic to capitalist reproduction. This differentiation between capital in general and private capital is but a difference in the level of abstraction under which the movement of the same category is observed. Thus, what is proposed in this paper is that, just as capital must be analyzed under a twofold aspect, that of appearance and essence, so too must the capitalist state gain the same treatment.
\end{abstract}

Keywords: Capitalist state; social form; political regime.

\section{INTRODUÇÃO}

O objetivo deste trabalho é apresentar uma leitura crítica do Estado capitalista, como forma social. Marx descreve e desenvolve no livro I d'O Capital, o capital em geral, que difere dos inúmeros capitais particulares que concorrem entre si na lógica de acumulação capitalista. Ainda que Marx faça esta diferenciação, tanto em sua principal obra, quanto em inúmeros de seus trabalhos, deve-se destacar que o capital em geral convive em todas as formas de capital, pois constitui sua natureza comum, que justamente diferencia o capital das outras formas de riqueza capitalista.

Portanto, pretendemos partir do mesmo nível de abstração, para compreender o Estado capitalista, não só como uma instituição político-jurídica, mas como uma forma social, intrínseca a produção capitalista. Esta diferenciação entre o capital em geral e os capitais 
particulares nada mais é que uma diferença do nível de abstração sob o qual se observa o movimento de uma mesma categoria.

Assim, o que se propõe neste trabalho, é que, da mesma forma que o capital deve ser analisado sob um duplo aspecto, o da aparência e o da essência, também o Estado capitalista deve ganhar o mesmo tratamento. Para atingir este objetivo, na segunda parte do texto, após a Introdução, apresentamos de forma sucinta alguns tópicos que julgamos centrais no debate marxista clássico acerca do Estado. Em seguida, retornamos à dialética hegeliana para compreender o que são formas sociais.

$\mathrm{Na}$ terceira parte do texto, apresentam-se as ideias centrais do trabalho de Mathias e Salama (MATHIAS \& SALAMA, 1983). O trabalho desenvolvido pelos autores contém uma perspectiva de análise que possibilita a interpretação do Estado como forma social. Os autores, partem da ideia de que o Estado deve ser interpretado como "abstração", e não como coisa ou instrumento de classe. Por trás desta ideia reside um caminho lógico no qual a natureza de classe do Estado deve ser "deduzida logicamente" não da luta de classes, mas sim do capital, “[...] concebido como categoria, nos países capitalistas desenvolvidos; ou [...] 'derivada' da 'economia mundial constituída', nos países subdesenvolvidos” (MATHIAS \& SALAMA, 1983, p. 15). Deduzir o Estado da economia mundialmente constituída é o tema trabalhado na quinta e última parte deste trabalho.

Ao percorrer este caminho, no final do artigo levantamos alguns limites que residem na não separação da forma e do conteúdo do Estado capitalista, do ponto de vista interpretativo.

\section{A QUESTÃO DO ESTADO NA TEORIA MARXISTA}

O tema do Estado divide o pensamento no interior das ciências humanas. Vai desde análises liberais até análises marxistas. Cada campo, por sua vez, subdivide-se em inúmeras perspectivas e teorias. Dentro do campo marxista, o Estado foi tema de trabalhos clássicos como os de Engels (ENGELS, 2010), Marx (1974; 2008a; 2008b; 2008c), Lênin (LÊNIN, 2007), 
Althusser (ALTHUSSER, 1895) e Poulantzas (POULANTZAS, 1977; 1980). A lista de obras clássicas do marxismo na análise do Estado não para por aqui. Em todo caso, mesmo dentro destas obras clássicas, o Estado ganha conotações diferentes e as análises em seu interior também ressaltam aspectos diferentes, ora analisando a natureza do Estado, ora tentando encontrar as suas origens, ora privilegiando os aspectos materiais, ora os elementos que o inserem como mais um elemento dentro da superestrutura.

De produto da "[...] necessidade de conter o antagonismo das classes" (ENGELS, 2010, p. 215), até tornar-se "[...] comitê que administra os negócios comuns da classe burguesa como um todo" (MARX \& ENGELS, 2008b), na sociedade capitalista, o Estado, desde seu surgimento na Idade Antiga, modificou-se radicalmente de forma tornando-se cada vez mais complexo em seu conteúdo.

Com as mudanças de forma, modificaram-se também as interpretações sobre sua natureza. De "classe dominante em armas”, "[...] órgão de dominação de classe, um órgão de submissão de uma classe por outra" (LÊNIN, 2007), até tornar-se um "estado ampliado" em Gramsci (GRAMSCI, 2015b; PORTELLI, 2002), envolvendo os aparelhos do Estado "restrito" (sociedade política) e de sua forma "ampliada" (sociedade civil), sem a qual, em sociedades capitalistas complexas, a dominação dos grupos sociais dominantes se desagregaria. 0 sentido e a amplitude das análises sobre o Estado foram modificando-se até tornarem-se a expressão política das contradições de classes (POULANTZAS, 1977; 1980).

Porém, diferente de outras categorias, tais como trabalho, mercadoria, ideologia, capital, luta de classes, que são abordadas no campo da filosofia marxista, o Estado ganhou um tratamento privilegiado no campo da política, em detrimento de sua compreensão como forma social. Não porque não houve um tremendo esforço em interpretá-lo. Mas sim, justamente, porque como se destacou esta categoria foi tratada predominantemente sob uma ótica instrumental.

Em geral, as obras mencionadas acima (consideras clássicas), analisam o Estado como "produto das contradições de classes", comum a todos os modos de produção fundados na 
divisão social do trabalho. Mesmo que alguns destes trabalhos tratem de algumas das funções específicas do Estado capitalista, tais como a função repressiva (ALTHUSSER, 1895), ou como expressão condensada das contradições de classe a "nível político" (POULANTZAS, 1980), acreditamos ser necessário um desenvolvimento da teoria do Estado, retomando a própria questão de qual é a natureza do Estado capitalista? Neste sentido, iniciamos a exposição apresentando o que se pode compreender por formas sociais.

\section{FORMAS SOCIAIS NA DIALÉTICA MARXISTA}

Cabe caracterizar inicialmente o que é dialética? Existe uma extensa bibliografia a respeito, por isso uma resposta adequada a esta questão envolveria uma longa pesquisa bibliográfica sobre o tema. Entrar nesta discussão foge aos propósitos do artigo. Assim, é emprestado de Adorno (ADORNO, 2010) duas “determinações” sobre seu entendimento acerca da dialética: por um lado é algo do próprio objeto, uma condição interna de sua existência; por outro, ela é um método de organização para o pensamento.

Assim, se é levado em conta estes dois âmbitos, pode-se compreender a dialética como uma relação entre sujeito que investiga e objeto investigado. Esta relação, contudo, é bastante complexa, e têm limites dos quais não se pode fugir. Pelo próprio movimento interno dos objetos, o sujeito pode no máximo oferecer conceituações e definições provisórias dos objetos estudados1.

Algo sempre resiste na coisa. Classificações, definições, determinações, identidades e conceitos deixam de fora algo do objeto. Isso ocorre tendo em vista que se nosso objeto é como o da Economia Política, por exemplo, as contradições internas à sua

\footnotetext{
1 Marx não escreveu uma obra específica e tão pouco deixou leis ou recomendações de cunho metodológico para desenvolvimento de pesquisas. 0 que o autor nos deixa ao longo da sua obra e vida, é o profundo exercício de captura da essência e da aparência da realidade social estudada (a sociedade civil burguesa e seu modo de produção), em suas múltiplas determinações. Ao fazer esse movimento de análise, Marx articula fundamentalmente três categorias: totalidade, contradição e mediação. Buscando apreender a lógica do processo de acumulação do capital e suas tendências futuras, apresentadas em sua principal obra, $O$ Capital. Nesta obra, o autor começa a analisar a sociedade burguesa, a partir da mercadoria, já que a sociedade capitalista aparenta ser uma enorme "coleção de mercadorias", para chegar ao longo da obra na essência do processo de acumulação capitalista (valor que se valoriza). Ele não parte a princípio do capital (relação social), mas chega a este, encontrando suas tendências de acumulação e formação. Desse modo, Marx, nos ajuda a compreender que o exercício da pesquisa precisa estar fundado na análise e compreensão do concreto vivido, uma vez que objeto de pesquisa tem existência objetiva, independente da consciência do pesquisado, sendo preciso desvelar ao longo da pesquisa a lógica da coisa (NETTO, 2011, p. 22).
} 
existência se colocam em movimento. Além disso restam as zonas de sombra não capturadas em uma dada definição e a diferença entre a unidade de um conceito e a multiplicidade das formas de existência e aparecimento dos objetos concretos (GUIMARÃES, 2018, p. 6).

0 Estado é uma forma social como tentaremos demonstrar mais à frente. Suas contradições internas estão em constante movimento. Não é possível "capturar" a complexidade de suas "zonas de sombra". Classificações e definições sobre ele têm caráter provisório. Novas determinações são acrescentadas à sua natureza ao longo dos séculos. Tratá-lo como forma social ao lado de formas já analisadas por distintas vertentes da dialética marxista possibilita, a nosso ver, melhor situá-lo no interior da sociedade na qual sua existência participa ativamente da reprodução das relações sociais fundamentais.

Mas como estudar uma forma social tão complexa como o Estado?

Os começos efetivamente tomados nas obras de autores da dialética podem nos informar bastante sobre a objetividade e o método. Na Ciência da Lógica, Hegel entende que é necessidade do próprio objeto da lógica um começo que seja feito com o Ser, puro, abstrato, imediato e indeterminado. Marx, por outro lado, diz nas Notas marginais ao Tratado de Economia Política de Adolfo Wagner que ele não parte dos conceitos, mas das formas sociais. Em $O$ Capital, ele começa com a mais aparente e simples das formas sociais com as quais a riqueza se mostra nas sociedades capitalistas: a mercadoria (GUIMARÃES, 2018, p. 12).

Com esta citação chegamos, finalmente, ao ponto necessário para avançar na exposição do Estado como forma social. A essência do Estado reside justamente na complexa relação entre seu ser e seu conceito. A essência, tomada desta maneira, tem forma de existir e, também, uma aparência.

Mas, a forma não é a própria existência, sendo só o processo de posição que leva a ela. Não houvesse a forma, o fundamento e a essência não poderiam aparecer. Não haveria aparência ou existência exterior que fazem uma objetividade inteligível, cognoscível (GUIMARÃES, 2018, p. 17).

Assim a essência do Estado, como forma social não tem uma existência exterior à aparência. A essência constitui parte do conteúdo e da existência das formas sociais. Esta compreensão é necessária, pois se interpretamos o Estado como forma social, isto tem uma dupla implicação. Em primeiro lugar ele tem uma essência (que reside na materialidade concretada do Estado, mas também está além dela, em uma relação dialética com a sua mediação histórica, social e política). Em segundo lugar esta essência está articulada por uma complexa relação entre seu ser e seu conceito, como vimos acima. 
Se tratarmos de um Estado capitalista, seu ser reside justamente nas relações mais profundas que constituem a sociedade capitalista. Nas suas relações fundamentais de produção que formam a base sobre a qual se eleva a superestrutura desta mesma sociedade. Estas relações, do ponto de vista abstrato, nada mais são que as relações de assalariamento características da sociedade capitalista.

A forma do Estado é o processo que permite compreendê-lo. A forma é "[...] um processo que permite haver unidade e identidade no caos contraditório de movimentos complexos, reflexivos e não idênticos" (GUIMARÃES, 2018).

A forma é a primeira mediação da aparência, o primeiro elo de sentido que faz com que a aparência do puramente empírico se vincule ao fundamento e à essência, para, só então, alcançar o nível do conceito. A aparência, por sua vez, é o revelar imediato das determinações da essência por meio das suas formas sociais (GUIMARÃES, 2018, p. 18).

Assim, chegamos à conclusão do que são as formas sociais:

[...] são processos de objetivação das relações sociais, que se estabilizam em uma unidade inteligível por meio das dinâmicas concretas que envolvem luta de classes, economia, política, valores, cultura, etc (GUIMARÃES, 2018).

Desta maneira, as "formas sociais são identificáveis nas aparências, nas estruturas sociais, nas leis de tendência, nas mediações concretas envolvidas nas relações sociais, nas identidades e contradições" (GUIMARÃES, 2018). Por isso, podemos afirmar que o Estado, mais que mero conceito, ferramenta ou instrumento, é um complexo de complexos que denominamos por forma social. É um conjunto de processos de objetivação das relações sociais dominantes (e fundamentais) em determinada sociedade. Sua aparência reside nas estruturas sociais (que muitas vezes são confundidas com sua própria essência), nas leis tendenciais internas, e nas relações que estabelece com a sociedade e o funcionamento econômico destas sociedades.

Ademais, a interpretação do Estado como forma social, sobre uma análise marxista, ainda precisa ser aprofundada. 0 caminho até esta conclusão passou pela obra do jurista soviético Evguiéni B. Pachukanis. Examinemos agora o caminho percorrido e a possibilidade que ele deixa em aberto para a compreensão do Estado como forma social.

\section{O DEBATE DA DERIVAÇÃO E O ESTADO "SUPERDESENVOLVIDO"}


Vimos que o Estado é uma forma social. O Estado capitalista na superfície da sociedade como aquilo que não é. Como uma instituição acima das classes sociais que tem como último objetivo regular e harmonizar conflitos e contradições de classe. Esta relação na qual ele aparece como aquilo que não é, assemelha-se à relação que a forma mercadoria mantém com os produtores do trabalho humano portadores de valor. É uma relação fetichizada, onde as relações sociais subjacentes aparecem como aquilo que não são.

Resta, entender porque isso também ocorre com a dominação entre classes sociais e qual é a relação que o Estado capitalista ocupa nesta relação. Ou simplesmente, resta retornar à pergunta de Pachukanis (PACHULANIS, 1988): por que a dominação de classe, no capitalismo, não aparece como aquilo que ela é, ou seja, como a dominação de uma parte da sociedade sobre as demais?

Duas respostas imediatas são possíveis. As duas, porém, são insatisfatórias. A primeira seria a de que a dominação de classe, no capitalismo encontra-se escondida ideologicamente. Esta resposta é descartada, pois o próprio Pachukanis indica que um "disfarce ideológico" já existia em outros modos de produção. A segunda resposta é a que resolve o problema afirmando que a natureza de classe do Estado é capitalista. De fato, esta é a natureza de classe do Estado no capitalismo. Mas não resolve o problema, pois é necessário estabelecer uma série de mediações até se chegar a esta afirmativa genérica. Vamos a elas.

Antes de avançar com o caminho de Pachukanis, destacamos que o próprio Marx dá indícios de interpretar o Estado como forma social, derivado de relações sociais características do capitalismo. Em “A ideologia alemã”, por exemplo, Marx demonstra que a sociedade civil se mostra como a expressão das trocas justas e é o próprio Estado a instituição capaz de garantir as trocas, na medida em que ele é a expressão da sociedade civil, ou, em outras palavras, o Estado "parece" expressar os interesses "gerais" de toda a sociedade, quando, na realidade, é a expressão dos interesses particulares da classe dominante em determinada época.

Agora, seguindo pelo caminho de Pachukanis, existe uma separação entre os capitais particulares e o Estado capitalista, "aparelho particular independente" dos capitais particulares. Estamos em vista da separação entre conteúdo abstrato geral e a forma particular de existência do capital. No primeiro nível, o capital em geral necessita, para 
reproduzir-se, deste "aparelho independente", mas que está ligado organicamente a ele, que é, justamente, o Estado. Contudo, o que conhecemos, pela sua intervenção e por seus infindáveis aparelhos, nada mais é que as forma como o Estado apresenta-se na sociedade: como regime político.

Esta separação é que permite compreender o que podemos chamar por fetiche da dominação de classe que se esconde sob a forma de um Estado "acima da sociedade civil", como Marx indica no "Prefácio" de 1859 (MARX, Contribuição à crítica da economia política, 2008a). Mas para compreender melhor, emprestamos o raciocínio elaborado por Mathias e Salama (1983) que implica em fazer uma dedução lógica2 do Estado a partir do capital.

Da mesma forma que o fetiche da mercadoria esconde as relações sociais subjacentes à mercadoria. Pode-se atribuir ao fetiche da dominação de classe a ilusão de que o Estado se apresente acima da sociedade de maneira imparcial para regular os conflitos entre indivíduos atomizados. Sobre esta relação Mathias e Salama (1983) escrevem que:

\begin{abstract}
Nesse raciocínio, a primeira questão que colocamos não é: "os trabalhadores são explorados?". Consideramos que eles são explorados. A questão pertinente torna-se: "por que os trabalhadores não percebem imediatamente sua exploração?"; "por que consideram que seu salário corresponde à remuneração de seu trabalho?"; "por que pensam que á uma simples relação de troca entre essas duas mercadorias?". A análise das raízes da coisificação revela o que há por trás da relação de troca e explica o fetichismo da mercadoria. Uma vez dada essa explicação, mostra-se o que é a exploração. Pode-se fazê-lo porque se mostrou primeiro o que servia de fundamento a essa troca. A exploração é inicialmente um dado que não é sentido espontaneamente como tal, e que pode em seguida ser explicado (MATHIAS \& SALAMA, 1983, p. 83).
\end{abstract}

A compreensão do fetiche da mercadoria possibilita compreender a natureza por trás da mercadoria. Porém, com a generalização da mercadoria que reside, basicamente, na transformação da força de trabalho em mercadoria sob a forma de assalariamento, e com a generalização por uma dada sociedade desse tipo de relação ou mesmo com a transformação do assalariamento em relação dominante, "os fetiches multiplicam-se". Vejamos:

Com a generalização da mercadoria, esses aspectos fetichizantes multiplicam-se. A relação de exploração é objetiva e espontaneamente ocultada. A relação de igualdade predomina. A exploração, se é que existe, aparece como um acidente que resulta de

2 "O Estado é assim concebido o é como uma categoria. Estamos em presença de uma dedução lógica. Essa é diferente da dedução histórica (materialismo histórico). Mas não é independente dela. Ela fornece as categorias necessárias à compreensão da história. Mas essas categorias se historicizam e sofrem a influência do decurso da história" (MATHIAS \& SALAMA, 1983, p. 24). 
um desrespeito das condições de igualdade da troca (por exemplo: monopólio e, mais particularmente, os sindicatos). É algo que deve ser condenado. A esse nível da análise, pareceria que o Estado é algo inútil se se põe além do papel que poderia lhe caber: o de garante das relações de troca, as quais - salvo acidente - são presumidas como igualitárias (MATHIAS \& SALAMA, 1983, p. 22).

E mais à frente.

A natureza do Estado é capitalista. Formulamos essa hipótese 0 Estado é, portanto, o garante da manutenção da relação de produção. Mas a troca mercantil e a extensão da forma mercadoria à força de trabalho - a generalização da mercadoria - fazem com que essa relação de produção não apareça como tal. Esse tipo de garantia não encontra, a esse nível de análise, nenhum fundamento lógico. 0 Estado está aí. Ele não é necessário, a não ser como gendarme que garante que as regras da troca aparentemente igualitárias não sejam violadas. Aparece como um instrumento neutro. 0 Estado capitalista aparece como "ao lado e acima da sociedade civil" (Marx). Essa ilusão é reforçada por vários fatores: onipresença hoje do Estado, relativa continuidade das administrações em relação à sucessão dos governos, nível atingido pela legitimidade desses últimos (MATHIAS \& SALAMA, 1983, pp. 22-23).

Ocorre que deduzir logicamente o Estado a partir do capital prescinde da sequência de categorias que, a priori desembocavam no capital, mas que não pode restringir-se nele3. Essa sequência lógica não se resolveria na realidade concreta (histórica) não fosse a existência do

\section{Estado4 como o demonstraremos a seguir. Vejamos:}

É por isso que a sucessão das categorias "mercadoria / valor / dinheiro" não pode se deter na categoria "dinheiro". Deve prosseguir. Depois do dinheiro, virá a categoria "capital". Como bem observa Rosdolsky: "A série 'mercadoria / valor / dinheiro / capital' enuncia simplesmente que cada uma das categorias ultrapassa a si mesma e nenhuma das categorias pode ser plenamente compreendida sem as anteriores". Assim, não se pode compreender verdadeiramente o dinheiro se não se recorre à categoria que lhe sucede. Inversamente, não se pode compreender o que é realmente o capital se não se realiza uma análise lógica do dinheiro. [...] 0 capital pode, então, ser concebido como uma relação social e não como uma simples soma de equipamentos (MATHIAS \& SALAMA, 1983, p. 23).

\section{Assim, chegamos ao resultado da dedução lógica do Estado ao capital:}

A generalização da mercadoria fornece as bases materiais para uma coisificação das relações de produção. 0 fetiche da mercadoria faz com que o Estado apareça como algo acima das classes sociais. A generalização da mercadoria não pode existir sem que exista - como pré-condição - desenvolvimento do capital. 0 capital é uma relação social. A acumulação de capital não exclui o jogo das classes sociais. Ela é, ao

3 "Sem a categoria "Estado", a categoria "capital" não pode ser concebida. O Estado é deduzido - ou, em outras palavras, derivado - do capital por duas razões: é o garante da manutenção das relações de produção e participa de modo decisivo na própria instituição dessas relações" (MATHIAS \& SALAMA, 1983, p. 24).

4 "Limitada à categoria "capital", essa dedução lógica não permite apreender em sua totalidade as causas do movimento real da sociedade. Não se pode - como o fez Marx - deter a sucessão das categorias no capital, e definir então as leis da acumulação" (MATHIAS \& SALAMA, 1983, p. 24). 
contrário, o produto da luta de classes; e, através dessa luta, ela influencia seu curso. A acumulação traduz e pesa sobre o desenvolvimento da contradição capital / trabalho. É por isso que acumulação de capital é um elemento desfetichizador das relações de produção. Ou seja: essa acumulação é capaz de revelar aos trabalhadores a realidade das relações de produção e de exploração e de suscitar a combatividade dos mesmos. A ilusão da troca igual se atenua como o que realmente é. A pseudoigualdade da relação de troca revela sua desigualdade no processo de produção. 0 fetichismo se faz acompanhar do seu contrário: o desfetichismo. 0 Estado é a resposta a essa desfetichização. Garantindo o respeito pelas regras da troca, ele garante a possibilidade da exploração e de sua perenidade (MATHIAS \& SALAMA, 1983, p. 25).

Por fim,

[O Estado] é o garante da perenidade das relações de produção. Sua intervenção se situa em vista dessa necessidade. Por isso, ele não pode se confundir com nenhum capital individual, por um lado, e, por outro, é necessariamente uma abstração, uma categoria. Representante dos interesses gerais do capital, pré-condição para seu desenvolvimento, ele é o "capitalista coletivo ideal" (Engels). Portanto, o Estado é uma abstração real, que se realiza - sob forma de regime político - no curso da luta de classes (MATHIAS \& SALAMA, 1983, pp. 26, grifo dos autores).

Com essas afirmações julgamos ter realizado, no plano abstrato (teórico), as mediações necessárias para afirmar que a natureza de classe do Estado no capitalismo é capitalista. Ainda que pareça uma redundância, esta afirmação é resultado desta sequência lógica. O Estado, derivado do capital, é uma abstração (ainda que real). Sua forma é o regime político. 0 regime político é produto (derivado) da luta de classes. Contudo, esta dedução ainda encontra um problema. Nos "países subdesenvolvidos" não existe a generalização da mercadoria. Assim, esta dedução do Estado, a partir do capital, precisa seguir outro caminho. Vejamos qual o caminho.

\section{ESTADO DEDUZIDO E ESTADO DERIVADO: DETERMINAÇÕES ECONÔMICAS DA FORMA SOCIAL DO ESTADO}

Nos países capitalistas subdesenvolvidos as relações de exploração da força de trabalho como o assalariamento, combinam-se uma variedade de relações de produção, tais como escravismo, colonato, regime de parceria, etc. Deve-se destacar também que,

Nos países que se tornaram subdesenvolvidos, o aparecimento e florescimento do modo de produção capitalista não foram gerados e produzidos pelo desenvolvimento das contradições internas. Esse modo de produção emergiu das entranhas da sociedade, mas foi de certo modo trazido do exterior: e foi precisamente isso que criou o subdesenvolvimento. Esse fato é hoje amplamente admitido (MATHIAS \& SALAMA, 1983, p. 29). 
Assim, “[...] Resulta dessa particularidade que a difusão das relações mercantis é incompleta e específica" (MATHIAS \& SALAMA, 1983, p. 29).

A difusão das relações mercantis nos países subdesenvolvidos - inclusive nos mais industrializados - alimenta-se da desestruturação que provoca nas relações de produção não capitalistas, num lapso de tempo extremamente breve. Ela as adapta (ou tenta adaptá-las), sem necessariamente transformá-las em relação de produção capitalista, à lógica de valorização do capital (MATHIAS \& SALAMA, 1983, p. 29).

Nas economias subdesenvolvidas, parcela considerável da força de trabalho reside estruturalmente no setor informal. Resquícios do passado colonial e escravocrata perduram no presente. As explicações para este fenômeno não se encontram na incapacidade que as elites locais têm de romper com a estrutura dependente de uma industrialização fraca, quando ela existe, ou com um retardamento no processo de interligar os vários setores da indústria entre si. O subdesenvolvimento não é uma etapa para o desenvolvimento, como alertava Gunder Frunk (FRANK, 1966)5. "O que qualifica o subdesenvolvimento não é a subindustrialização, nem a "falsa" industrialização (sic.), nem o dualismo tecnológico, etc., mas sim esse processo" (MATHIAS \& SALAMA, 1983, pp. 29-30). Qual processo? 0 do momento e da forma como se difundem as relações mercantis a partir de fora nas economias, no passado coloniais ou dependentes, e atualmente, subdesenvolvidas. 6

É essencial tomar em consideração os elementos que engendram (e depois influem sobre) o processo de subdesenvolvimento. É por isso que não se pode aceitar a hipótese de generalização da mercadoria. Isso implicaria em deixar de lado precisamente o que constitui o subdesenvolvimento (MATHIAS \& SALAMA, 1983, p. 31).

Assim,

Embora recusemos a escola da derivação para o caso dos países subdesenvolvidos, essa consideração é fundamental. Para sermos claros: a inexistência de uma classe pode não afetar a natureza de classe do Estado. Pode haver um Estado capitalista sem classe capitalista. A natureza de classe do Estrado é conferida por outros fatores que não a existência de uma formação social apropriada. [...] Todavia, é evidente que a inexistência de uma classe social tão fundamental como a dos capitalistas, ou dos operários, ou sua quase inexistência, ainda que não influa sobre a natureza de classe do Estado, influi profundamente sobre sua forma de existência: manifesta-se na

5Versão em português disponível em:

http://beneweb.com.br/resources/Teorias_e_experi\%C3\%AAncias_de_desenvolvimento/7\%20Andr\%C3\%A9 \%20Gunder\%20Frank\%20 \%20desenvolvimento\%20do\%20subdesenvolvimento.pdf. Acesso em 11/01/2019. 6 Aqui ainda se está tratando sob o nome de subdesenvolvidas uma série de nações muito diferentes entre e que engloba a maior parte das nações do mundo. Mais à frente serão selecionados alguns casos para comparação e, analisar, especificamente a intervenção pública no Brasil. Ou seja, estamos ainda no plano abstrato. 
produção de regimes políticos próprios, originais (MATHIAS \& SALAMA, 1983, pp. 3132).

Então, se não se pode deduzir o Estado do capital, nestes casos, como compreender a natureza do Estado? O Estado, nos países subdesenvolvidos é deduzido (ou derivado) do capital em nível mundial, ou da "economia mundial constituída"7.

A dedução lógica do Estado nos países subdesenvolvidos relaciona a economia mundial "constituída" e a natureza de classe desses Estados. Ela permite compreender por que o Estado é o lugar de difusão das relações mercantis e o elemento necessário a essa difusão. Ela esclarece de modo novo o papel do Estado na acumulação e as formas que ele assume (MATHIAS \& SALAMA, 1983, p. 39).

Assim,

A economia mundial é vital para o prosseguimento do processo de acumulação no centro, quando esse último atinge certa fase do desenvolvimento de suas forças produtivas. Essa fase é a do imperialismo. Chamamos a economia mundial que atingiu essa fase de economia mundial constituída. A partilha do mundo é efetuada entre as principais potências do centro. A economia de exportação se põe na ordem do dia. A difusão das relações mercantis substitui a economia de pilhagem. Os mecanismos de assalariamento substituem a escravidão, acomodando-se em maior ou menor medida ao trabalho forçado. O subdesenvolvimento se aprofunda (MATHIAS \& SALAMA, 1983, p. 41).

Desse modo, nos países desenvolvidos (ou imperialistas) o Estado é deduzido (ou derivado do capital em geral). Já nos países subdesenvolvidos (ou dependentes) o Estado é derivado do capital em geral em nível mundial (ou simplesmente, da economia mundial constituída). Desta forma, temos que:

7 "A economia mundial é composta de nações e se dá no seio dessas nações, de Estados. Uma dessas partes comumente chamada de 'centro' - é composta por Estados-Nação desenvolvidos; uma outra, por Estados-Nação subdesenvolvidos, sendo qualificada como 'periferia'. Nenhuma dessas partes é homogênea. Existem relações de dominação no seio do centro entre as economias desenvolvidas e no interior da periferia entre economias subdesenvolvidas. 0 que as qualifica como desenvolvidas ou subdesenvolvidas reside nas diferentes condições de emergência da acumulação, e, sobretudo hoje, nos diferentes efeitos dessa acumulação segundo o polo onde ela se realiza" (MATHIAS \& SALAMA, 1983, p. 39). 
QUADRO 1. Síntese Analítica do Estado como forma social

\begin{tabular}{|c|c|c|c|}
\hline NÍVEI DE ABSTRAÇÃO & \multicolumn{2}{|c|}{ DETERMINANTES } & CATEGORIA SOCIAL \\
\hline Abstrato & Mercadoria & Capital em geral & Estado \\
\hline Concreto & RSP8 & Luta de classes & Regime Político \\
\hline
\end{tabular}

Fonte: elaboração própria

Pela proposta expressa no quadro acima o Estado capitalista, em sua essência, ganha uma nova interpretação situando-se no mesmo nível de abstração que outras formas sociais (categorias) largamente desenvolvidas por Marx, tais como o dinheiro, a mercadoria, o trabalho e o capital. Esta separação, como destacado no texto, é meramente analítica. Tanto o Estado, quanto o regime político, pertencem convivem dentro da mesma forma social. A natureza do Estado, derivado do capital, determina sua forma, o regime político. As mercadorias, produto do trabalho humano, são produtos das relações sociais capitalistas de produção.

O que se propõe acima, é apresentar um esboço sintético de uma proposta alternativa de interpretação do Estado capitalista, que seja coerente com o que Marx propôs e que consiga dar conta de ajudar a interpretar as contradições capitalistas do mundo contemporâneo.

\section{CONSIDERAÇÕES FINAIS}

Com base nas discussões do Estado como forma social cabe, ainda, uma última consideração. A separação realizada entre a aparência e a essência do Estado, tem efeito meramente analítico, dado que o Estado, como forma social, engloba organicamente sua essência e sua aparência. Desconsiderar, contudo, que o Estado, forma social, é diferente de sua forma concreta implica uma dupla limitação. 
Em primeiro lugar, as teorias marxistas clássicas sobre o Estado, como discutimos neste artigo, podem ser consideradas em sua maioria "instrumentalistas", pois sem baseiam centralmente, na função política do Estado, na sociedade capitalista. Esta instrumentalização por parte destas teorias limita a interpretação das formas do Estado em três pontos:

1. O primeiro é o limite para a compreensão sobre as mudanças das formas de Estado em períodos muitos extensos.

2. O segundo ponto impede de diferenciar estas mudanças ao longo de períodos mais curtos, tais como as transformações que ocorrem nas formas de Estado de um governo para outro.

3. Por fim, limita também a investigação sobre como o Estado intervém na sociedade, e as funções que cumpre esta intervenção.

A segunda limitação diz respeito ao fato de que, ao fazer esta separação, abre-se a possibilita de colocar em dois distintos níveis de abstração os fatores que determinam a intervenção, tanto do Estado, quanto do regime político na sociedade. E por que seria necessária esta separação? Porque situá-los no mesmo nível de abstração leva a uma conclusão equivocada, ainda que bastante generalizada, de que a intervenção do Estado na sociedade pode "apaziguar" a luta de classes quando, na realidade, é a intervenção de sua forma (regime político), sob o nome de intervenção pública que pode cumprir este papel. 0 Estado, no nível abstrato, em situação de organicidade em relação ao capital, é o garantidor de suas relações de produção fundamentais.

A luta de classes, por sua vez, tem um movimento mais dinâmico que as transições estruturais que levam às mudanças dos modos de produção. E, como sabemos, a natureza do Estado acompanha estas transições. Assim também é possível compreender porque é o regime político, forma do Estado, que sofre a influência do desenvolvimento da luta de classes e não propriamente o Estado.

Assim, um modo de produção em crise, não consegue sobreviver sem que o Estado garanta as relações fundamentais deste modo produção. Ou, invertendo o raciocínio: não pode haver um Estado fora de lugar em relação ao modo de produção. Ou ainda, simplesmente, o Estado desenvolve-se no interior de um determinado modo de produção sendo, deste modo, sua parte integrante. Ele pode garantir a reprodução das relações de 
produção fundamentais deste modo de produção ou mesmo criá-las onde elas ainda não existem de maneira generalizada.

\section{REFERÊNCIAS}

ADORNO, T. W. (2010). Dialética negativa. São Paulo: Jorge Zahar.

ALTHUSSER, L. (1895). Aparelhos ideológicos do Estado. São Paulo: Graal.

ENGELS, F. (2010). A origem da família, da propriedade privada e do Estado. São Paulo: Expressão Popular.

FRANK, A. G. (September de 1966). 0 desenvolvimento do subdesenvolvimento. Monthly Review, 18(4), 14.

GRAMSCI, A. (2015a). Cadernos do cárcere: volume 1. Rio de Janeiro: Civilização Brasileira. GRAMSCI, A. (2015b). Cadernos do cárcere: volume 3. Rio de Janeiro: Civilização Brasileira. GRAMSCI, A. (2015c). Cadernos do cárcere: volume 4. Rio de Janeiro: Civilização Brasileira. GUIMARÃES, L. F. (junho de 2018). A dialética entre o método e a realidade: Um projeto para organizar a contradição. XXIII Encontro Nacional de Economia Política.

LÊNIN, V. (2007). O Estado e o revolução. São Paulo: Expressão Popular.

MARX, K. (1974). 018 Brumário de Luís Bonaparte. São Paulo: Abril Cultural.

MARX, K. (2008a). Contribuição à crítica da economia política. São Paulo: Expressão Popular.

MARX, K., \& ENGELS, F. (2008b). Manifesto do Partido Comunista. São Paulo: Expressão Popular.

MARX, K. (2008c). 0 capital: crítica da economia política. O processo global de produção capitalista. Livro III (Vol. 5). Rio de Janeiro: Civilização Brasileira.

MATHIAS, G., \& SALAMA, P. (1983). O Estado Superdesenvolvido: das metrópoles ao terceiro mundo. São Paulo: Brasiliense.

NETTO, José Paulo. Introdução ao estudo do Método de Marx. São Paulo: Expressão Popular, 2011. 
PACHULANIS, E. B. (1988). Teoria Geral do Direito e Marxismo. São Paulo: Acadêmica.

POULANTZAS, N. (1977). Poder político e classes sociais. São Paulo: Martins Fontes.

POULANTZAS, N. (1980). O Estado, o poder e o socialismo. São Paulo: Graal.

Submetido em: 09/08/2019

Aprovado em:25/09/2019 